International Journal of Engineering \& Technology, $7(2.31)(2018) 34-36$
SPC
International Journal of Engineering \& Technology
Website: www.sciencepubco.com/index.php/IJET
Research paper

\title{
Study and analysis of novel RF MEMS switched capacitor
}

\author{
K. Vikas ${ }^{1 *}$, S. Sunithamani ${ }^{2}$, M. Yagnika ${ }^{3}$, S. Siva Krishna ${ }^{4}$, S. Avanthi ${ }^{5}$ \\ ${ }^{I}$ Department of ECE, Koneru Lakshmaiah Education Foundation, Vaddeswaram, Guntur, Andhra Pradesh, India. \\ ${ }^{2}$ Department of ECE, Koneru Lakshmaiah Education Foundation, Vaddeswaram, Guntur, Andhra Pradesh, India. \\ ${ }^{3}$ Department of ECE, Koneru Lakshmaiah Education Foundation, Vaddeswaram, Guntur, Andhra Pradesh, India. \\ ${ }^{4}$ Department of ECE, Koneru Lakshmaiah Education Foundation, Vaddeswaram, Guntur, Andhra Pradesh, India. \\ ${ }^{5}$ Department of ECE, Koneru Lakshmaiah Education Foundation, Vaddeswaram, Guntur, Andhra Pradesh, India. \\ *Corresponding author E-mail:14004513@kluniversity.in
}

\begin{abstract}
In this paper we have designed and analyzed shunt capacitive fixed-fixed RF MEMS switch to maintain low actuation voltage. The pull in voltage of the proposed switch is $7.7 \mathrm{~V}$ for $2 \mathrm{um}$ air gap. The electromagnetic analysis for the designed structure is, return loss is $-23 \mathrm{~dB}$ in the range of $1-40 \mathrm{GHz}$, insertion loss is $-0.04 \mathrm{~dB}$ at a frequency range of $1-40 \mathrm{GHz}$ and isolation is - $38.5 \mathrm{~dB}$ obtained at a frequency of 23.5 GHz. Mechanical analysis for the designed structure is also performed using FEM tool.
\end{abstract}

\section{Introduction}

Radio Frequency devices has a predominant role in the current scenario, these RF MEMS Switches are designed under Microwave Applications with a range of frequencies from $30 \mathrm{KHz}$ to $300 \mathrm{GHz}$ [1]. These are highly recommended for wide range of applications like Mobile phones, LAN's, Radar Applications, Satellite Communications and in automotive industries. This is due to their low power consumption, Low noise, Low insertion loss, high Isolation and ultra-wide frequency range which leads RF MEMS switches better when compared with traditional FETs and PIN diodes in many applications [2].

These conventional Switches weakens the RF characteristics of the following device. To overcome these, we have shifted to RF MEMS switches. MEMS switches are categorized as series and shunt capacitive switches based on their electrical

configurations. Direct metal to metal contact switches attain ohmic contact between two electrodes. Which leads to a limiting upper operating frequency up to $40 \mathrm{GHz}$ [3]. To avoid this, taking dielectric layer between the electrodes is the best choice which is nothing but a capacitive type switch. The designed Switch with a low Pull - in voltage of $9 \mathrm{~V}$, return loss in up and down state is $21 \mathrm{~dB}$ and $0.98 \mathrm{~dB}$ respectively [4], High Isolation up to $15 \mathrm{~dB}$ at a frequency of 10GHz.In a Novel Seesaw-type [5]

Capacitive RF MEMS switch was designed with a low actuation voltage up to $5 \mathrm{~V}$, Insertion loss is $0.5 \mathrm{~dB}$ at $10 \mathrm{GHz}$, return loss in down state is $0.5 \mathrm{~dB}$ at $10 \mathrm{GHz}$ and High Isolation is $28 \mathrm{~dB}$ at a frequency of $2.3 \mathrm{GHz}$. The Highly Stabilized MEMS switch designed with low actuation voltage up to $3 \mathrm{~V}$ [6], Return loss in up-state is $10 \mathrm{~dB}$ at $10 \mathrm{GHz}$, Insertion loss is $0.37 \mathrm{~dB}$ at $10 \mathrm{GHz}$ and high isolation up to $40 \mathrm{~dB}$ at a frequency of $10 \mathrm{GHz}$. The switch with a low actuation voltage up to $3.7 \mathrm{~V}$ [7], Return loss in up and down states is $15 \mathrm{~dB}$ and $0.99 \mathrm{~dB}$ at $10 \mathrm{GHz}$ respectively, High Isolation is $12.5 \mathrm{~dB}$ at $10 \mathrm{GHz}$. The Con Coff Ratio RF MEMS shunt switches designed at a low actuation voltage up to $10 \mathrm{~V}$, return loss is $35 \mathrm{~dB}$ at $10 \mathrm{GHz}$ and High Isolation $20 \mathrm{~dB}$ at a frequency of $10 \mathrm{GHz}$ [8-11]

In this paper, RF MEMS switch is designed with capacitive type switch in a micro-strip configuration. This proposed switch leads to low actuation voltage of $7.7 \mathrm{~V}$ for 2 um with having beam material as Gold $(\mathrm{Au})$. Electro mechanical of switch has very low actuation voltage and decent RF performance analysis have been performed.

\section{Structure of RF MEMS Switch}

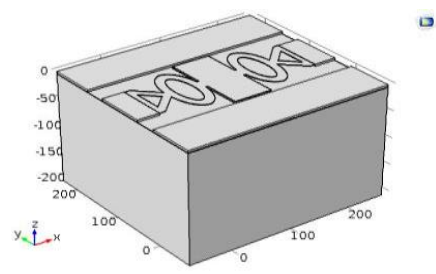

Fig. 1: Structural model of RF MEMS switch

The capacitive type fixed - fixed RF MEMS switch is outmost preferred switch for high capacitance ratio during OFF and ON respectively. The schematic model of switch described in the below figure. This schematic model consists of movable beam, dielectric, two anchors and substrate [9].

\section{Results and discussions}

\section{Stress distribution analysis}

To study the mechanical properties of the proposed structure, a maximum force of 5.28E-6 is applied to displace the beam for 2 um air gap. The graphs for Displacement and Spring constant across the force range of $0-5.28 \mathrm{E}-6$ is observed and plotted.

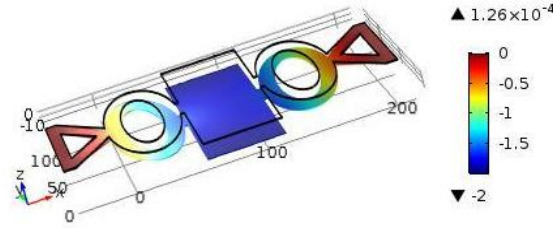

Fig. 2: Displacement of the switch with 2 um air gap 


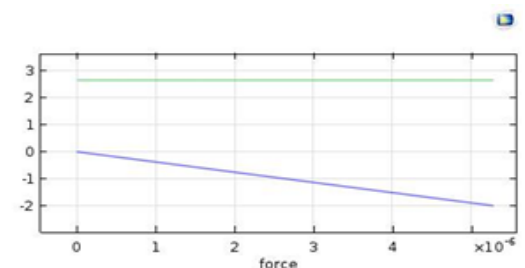

Fig. 3: Displacement and spring constant plots of the switch with 2 um air gap

\section{Electromechanical analysis}

The fixed-fixed capacitive shunt switch was designed and simulated using FEM Tool. A DC voltage is applied between micro strip and top electrode. It pulls down the membrane to get contact to dielectric layer enabling the OFF condition of the switch [10]. We have used as $\mathrm{SiO} 2$ and $\mathrm{Si} 3 \mathrm{~N} 4$ as dielectric material because it ishaving high dielectric constant which increases the OFF-state capacitance. The static electromechanical analysis of the proposed switch with air gap $(2 \mathrm{~m})$ deformed structure is shown below and the results are tabulated below.

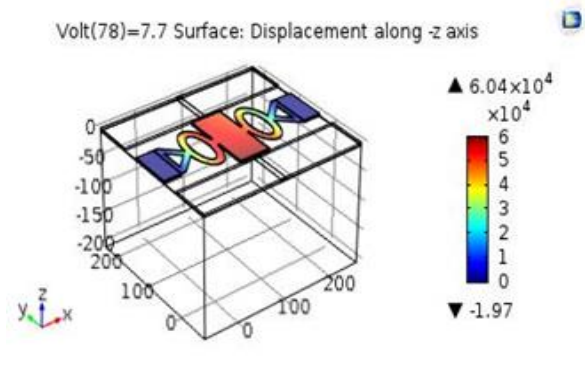

Fig. 4: Displacement of the switch with 2 um air gap

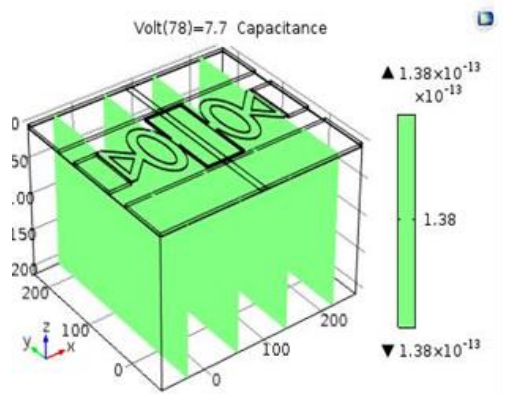

Fig. 5: Capacitance of the Switch with 2 um air gap The displacement and capacitance graphs with different voltages are shown in Fig (6) The proposed structure's pull-in voltage is observed at $7.7 \mathrm{~V}$. The graphs for Displacement and Capacitance across the voltage range of $0-7.7 \mathrm{~V}$ is observed and plotted.

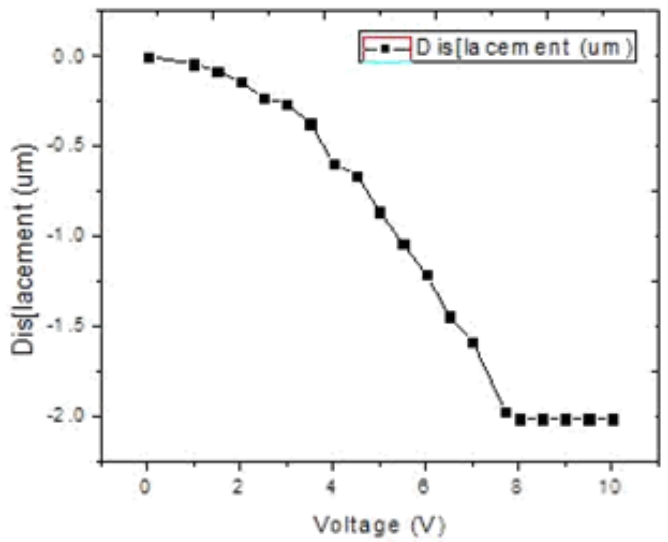

Fig. 6: Displacement of the switch with 2 um air gap electromagnetic analysis

RF analysis are done by using Ansoft HFSS. The Scattering parameters are essential over a wide range of frequency. When no voltage is applied across the beam the switch will be ON state, the insertion and return losses of ON state switch at $2 \mathrm{~m}$ gap with silicon nitride as a dielectric layer at $1-40 \mathrm{GHz}$ frequency range are measured. Switch gives the return loss of greater than $-23 \mathrm{~dB}$ with silicon nitride as dielectric material. Fig shows the excellent insertion loss of $-0.045 \mathrm{~dB}$ over a frequency range of $1-40 \mathrm{GHz}$. When switch undergoes actuation voltage, beam collapsed on to the dielectric layer over the signal line, thus switch undergoes OFF state and signal will not transfer from one state to another state. The isolation of the switch will be measured on the OFF state and it is $-38.5 \mathrm{~dB}$ obtained at a frequency of $23.5 \mathrm{GHz}$

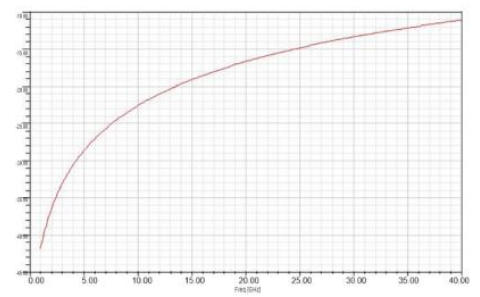

Fig. 7: Return loss in UP state

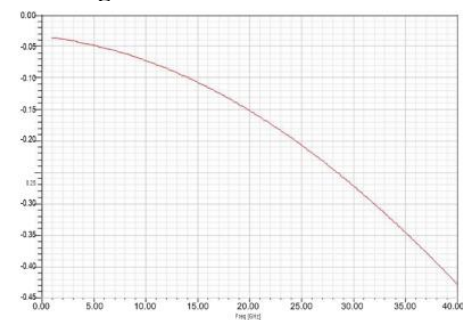

Fig. 8: Insertion loss in UP state

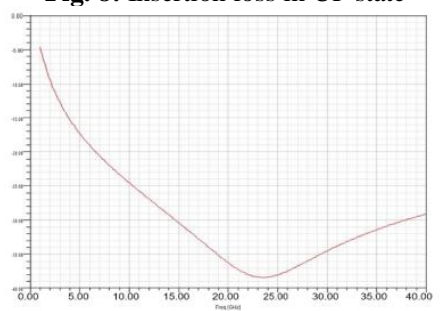

Fig. 9: Isolation of the switch in down state

\section{Conclusion}

Our paper describes a fixed - fixed switch designed and simulated using FEM tool to obtain low pull-in Voltage, and better RF performance Characteristics at different air gaps. From the simulated results, it is observed that the pull-in voltage is $7.7 \mathrm{~V}$ for 2 um air gap. The S-parameter results are the return loss (S11) is greater than $-23 \mathrm{~dB}$, the insertion loss is less than $-0.045 \mathrm{~dB}$ in the range of 1 to $40 \mathrm{GHz}$ frequency and isolation $(\mathrm{S} 21)$ is $-38.5 \mathrm{~dB}$ at $23.5 \mathrm{GHz}$ frequency. From the above observation the switch can be implemented for antennas in $\mathrm{K}$ Band Applications.

\section{Acknowledgment}

The authors thank National MEMS Design Centre under NPMASS, which is supported by Indian Institute of Science, Bangalore, Govt. of India for providing necessary software tools for design.

\section{References}

[1] Rebeiz GM, RF MEMS: theory, design and technology, Wiley, New Jersey, (2003).

[2] Huff GH \& Bernhard JT, "Integration of Packaged RF MEMS Switches With Radiation Pattern Reconfigurable Square Spira Microstrip Antennas" IEEE Transactions on Antennas and Propagation, Vol.54, No.2, (2006)

[3] Rebeiz GM \& Muldavin JB, "RF MEMS switches and switch circuits", IEEE Microw Mag, Vol.2, No.4,(2001), pp.59-71

[4] Persano A, Cola A, Angelis G, Taurino A, Siciliano P \& Quaranta F, "Capacitive RF MEMS switches with Tantalum based 
materials", J MicroelectromechSyst, Vol.20, No.2, (2011), pp.365370.

[5] Pacheco S, Nguyen CT \& Katehi LPB, "Design of Low Actuation Voltage RF MEMS Switch", IEEE MTT-S International Microwave Symposium Digest, Baltimore, (2000), pp.165-168

[6] Cabral JM \& Holmes AS, "A Novel Seesaw-Type RF MEMS Switch", Proc. Melecon, Malaga, Spain, (2006), pp. 288-292

[7] Mishra B \& Panigrahi R, "Highly Stabilized MEMS Switch with Low Actuation Voltage", International Journal of Recent Trends in Engineering, Vol.2, No.7, (2009), pp.120-122

[8] Cho IJ, Song T \& Baek SH, "A Low-Voltage and Low-Power RF MEMS Series and Shunt Switches Actuated by Combination of Electromagnetic and Electrostatic Forces", IEEE Transactions on Microwave Theory and Techniques, Vol.53, No.7,(2005), pp.24502457

[9] Giacomozzi F, Calaza C, Colpo S, Mulloni V, Collini A, Margesini B, Farinelli P, Casini F, Marcelli R, Mannocchi G \& Vietzorreck L, "Development of high con coff ratio RF MEMS shunt switches", Romanian Journal of information science and technology, Vol.11, No.2,(2008), pp.143-151.

[10] Casini F, Marcelli R, Mannocchi G \& Vietzorreck L, 'Tecnological and Design Improvements for RF MEMS Shunt Switches", IEEE International Semiconductor Conference, (2007), pp.263-266

[11] Girija Sravani K \& Srinivasa Rao K, "Analysis of RF MEMS shunt capacitive switch with uniform and non-uniform meanders", Microsystems technologies, Springer Publisher, (2018).

[12] Laxminaryana T, GirijaSravani K \& Srinivasa Rao K, "A Micro Level Electrostatically Actuated Cantilever and Metal Contact Based Series RF MEMS Switch for Multi-Band Applications", Cogent Engineering Journal, Taylor and Francis Publishers, Scopus and SCI Index, (2017). 